\title{
IBD2020 global forum: results of an international patient survey on quality of care
}

\author{
Peter Irving ${ }^{1}$, Johan Burisch ${ }^{2}$, Richard Driscoll ${ }^{3 \dagger}$, Mats Olsson ${ }^{4}$, John R Fullarton ${ }^{5}$, Barry S Rodgers-Gray ${ }^{5}$, \\ Simon PL Travis ${ }^{6}$ \\ ${ }^{1}$ Department of Gastroenterology, Guy's and St Thomas' NHS Foundation Trust, London, UK, ${ }^{2}$ Digestive Disease Centre, Medical Section, \\ Herlev University Hospital, Copenhagen, Denmark, ${ }^{3}$ New Barnet, Greater London, UK, ${ }^{4}$ Kairos Future, Stockholm, Sweden, ${ }^{5}$ Strategen Limited, \\ Basingstoke, ${ }^{6}$ Translational Gastroenterology Unit, Oxford University Hospitals, Oxford, UK
}

Background/Aims: IBD2020 is a global forum for standards of care in inflammatory bowel disease (IBD). The aim of the IBD2020 survey was to identify and describe variations in quality care of IBD. Methods: Patients with IBD from Finland, Italy, France, Canada, Germany, UK, Spain and Sweden were surveyed during 2013 to 2014, covering: disease characteristics; impact on life and work; organization and perceived quality of care. Results: Seven thousand five hundred and seven patients participated (median age, 39 years [range, 10-103 years]; 2,354 male [31.4\%]), including 4,097 (54.6\%) with Crohn's disease (CD) and 3,410 (45.4\%) with ulcerative colitis (UC). Median time from symptom onset to diagnosis was 1 year for both CD (range, 0-47 years) and UC (range, 0-46 years), with no clear evidence of improvement in diagnostic delay over the preceding 24 years. Half of the patients $(3,429 ; 50.0 \%)$ rated their care as "excellent" or "very good," with similar results for CD and UC across countries. Five factors were significantly $(P<0.01)$ associated with perceived good quality of care: quality of specialist communication; review consultation being long enough; failure to share information; no access to a dietician; speed of advice. Conclusions: The IBD2020 survey has highlighted areas related to quality of care of IBD from the patients' perspective, with scope for improvement. (Intest Res 2018;16:537-545)

Key Words: Inflammatory bowel disease; Crohn disease; Colitis, ulcerative; Surveys and questionnaires; Quality of health care

\section{INTRODUCTION}

To deliver quality care for IBD, increasing sophistication, coordination and collaboration is required as therapeutic options and monitoring techniques increase. Indeed, improvements in quality of care are essential to meet the needs and expectations of the growing population of patients with IBD. ${ }^{1}$ Although there is evidence of improving care for IBD as a whole, variability and inconsistency in management persist, both within and between regions and countries. ${ }^{2-10}$ Time to

Received March 25, 2018. Revised June 2, 2018. Accepted June 15, 2018. Correspondence to Simon PL Travis, Translational Gastroenterology Unit, John Radcliffe Hospital, Oxford OX3 9DU, UK. Tel: +44-1865-228753, Fax:+44-1865-751100,E-mail: simon.travis@ndm.ox.ac.uk

${ }^{+}$Deceased. diagnosis and treatment, ${ }^{6}$ adherence to best practice guidelines, ${ }^{3}$ and access to multidisciplinary teams ${ }^{7}$ are some of the areas with scope for improvement. Initiatives in Europe, the US and elsewhere to improve care for patients with IBD include the development of quality measures to standardize processes, ${ }^{11-13}$ outcome measures, ${ }^{14}$ health systems that enable data sharing between patients and providers, ${ }^{15-17}$ and holistic, patient-centered care models. ${ }^{18-20}$

IBD2020 was established to provide a global forum for professionals and patients to share best practices and lessons learned in quality improvement, better to harmonize and align overall standards of care for IBD. The IBD2020 survey was undertaken to identify and describe deficits or variations in good quality care for patients with IBD, to provide a basis from which to measure progress.

\footnotetext{
๑ Copyright 2018. Korean Association for the Study of Intestinal Diseases. All rights reserved.

This is an Open Access article distributed under the terms of the Creative Commons Attribution Non-Commercial License (http://creativecommons.org/licenses/by-nc/4.0)

which permits unrestricted non-commercial use, distribution, and reproduction in any medium, provided the original work is properly cited.
} 


\section{METHODS}

\section{Survey Design}

The IBD2020 survey (June 2013-June 2014) consisted of 67 core questions designed to capture patient perspectives on quality of care related to: (1) disease characteristics (diagnosis, severity of condition, current medication); (2) effect on work and life; (3) organization of care; (4) information provision and access to a multidisciplinary team (MDT); or (5) perception of quality of care (overall, communication, coordination).

The questionnaire was designed by Richard Driscoll (then co-chair of IBD2020, former CEO Crohn's \& Colitis UK), based on previous questionnaires to Crohn's \& Colitis UK members and other patient-based questionnaires. ${ }^{21,22}$ All questions were closed with multiple choice answers. The English questionnaire (Supplementary Material 1) was piloted for plain language and comprehensibility among 10 patient-volunteers. Patients from 8 countries (Canada, Finland, France, Germany, Italy, Spain, Sweden, and UK) were invited to participate, which was carried out in association with respective national patient associations. The questionnaire was available online, translated into native languages by the patient associations, with invitations sent via email, Facebook, or letter.

\section{Statistical Analysis}

Questionnaires with missing data relating to diagnosis and/ or with $\geq 95 \%$ overall missing data were excluded from analyses. Answers were summarized based on the total number of respondents to each question, with those patients missing data for a question excluded from that particular analysis. Reported rates of unemployment were compared against national averages for June 2014. ${ }^{23,24}$ A primary diagnosis of any form of colitis was grouped under UC, irrespective of whether CD was also reported. The reliability of the questionnaire was tested by calculation of Cronbach $\alpha$.

Comparison of responses between groups was by chisquare test, Mann-Whitney $U$-test, Spearman correlation, Kruskal-Wallis H test, linear regression, ANOVA and by calculation of $\mathrm{OR}$, as appropriate. Binary logistic regression was used to determine factors associated with perceived quality of care. Quality of care was the dependent variable using combined "excellent" plus "very good" score: 1, and "good," "fair" or "poor" score: 2 , with the other variables (e.g., MDT access) used as categorical covariates, and OR calculated.

All analyses were carried out using Excel 2010 (Microsoft, Redmond, WA, USA) and SPSS for Windows 15.0 (SPSS Inc.,
Chicago, IL, USA).

\section{Ethical Aspects}

The survey of voluntary patient responses did not require formal ethical approval. All participants gave freely of their time, could stop completing the questionnaire at any stage, and consented for their responses to be included in the analyses of the aggregated data. All data were collected anonymously.

\section{RESULTS}

\section{Demographics}

Overall, 7,507 patients took part in the survey comprising 1,308 (17.4\%) respondents from Canada, 1,212 (16.1\%) from Finland, 1,064 (14.2\%) from Italy, 929 (12.4\%) from France, 887 (11.8\%) from Germany, 851 (11.3\%) from the United Kingdom, 661 (8.8\%) from Spain, and 595 (7.9\%) from Sweden (Table 1). A further 717 questionnaires were excluded due to missing data. Since the questionnaire was openly available, the response rate to the survey could not be determined. Cronbach $\alpha$ coefficient for the sections of the questionnaire dealing directly with the respondents' assessment of the quality of service provision was 0.69 , indicating relatively good reliability.

Of the 7,507 patients, 2,354 (31.4\%) were male and the median age of all respondents was 39 years (range, 14-103 years). CD was the primary diagnosis in 4,097 patients (54.6\%) and 3,410 (45.4\%) had UC. The median duration of disease was 8 years (range, $0-60$ years). At the time of completing the questionnaire, 1,227 patients (16.4\%) were smokers, with the rate being significantly higher $(P<0.001)$ in those with CD $(871,21.3 \%)$ than UC $(356,10.5 \%)$ (Supplementary Table 1).

Over half (3,664/6,178 [excluding Canada], 59.3\%) of the respondents were members of a patient organization, with respondents from Finland most likely to give an affirmative answer $(1,091 / 1,207,90.4 \%)$ and those from the United Kingdom being least likely (302/850, 35.5\%).

\section{Disease Characteristics}

Median time to diagnosis from first seeking medical care for symptoms was 1 year for both CD (range, 0-47 years) and UC (range, 0-46 years) and, assessed by date of diagnosis, was similar over the past 24 years $(P=0.319)$ (Fig. 1). However, when analyzed based on onset of symptoms, rather than date of diagnosis, there was a significant improvement in mean time to diagnosis for both CD and UC with advancing 


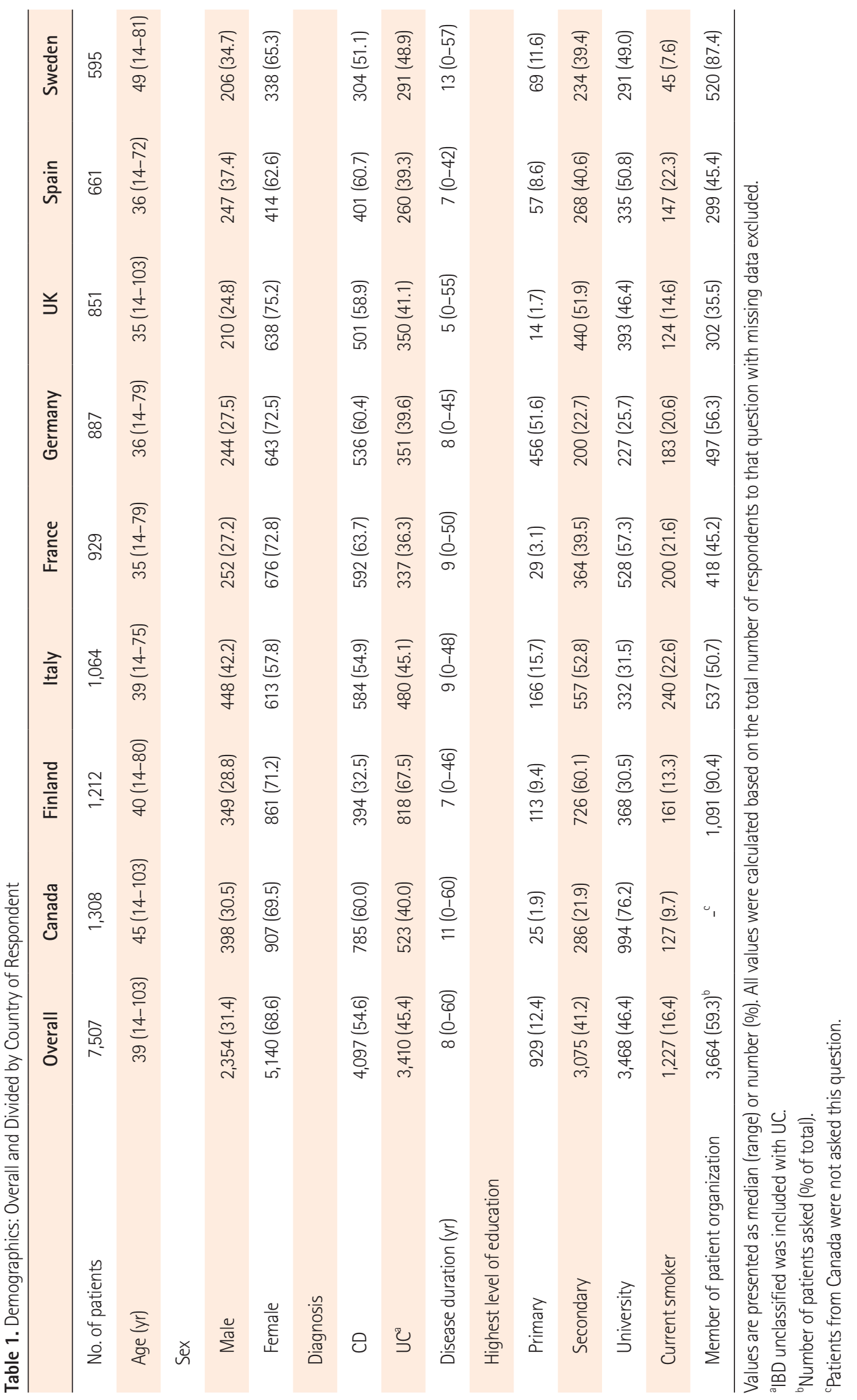


time (both $P=0.001$ ) (Supplementary Table 2). More than half of the patients $(4,221 ; 56.7 \%)$ sought emergency care prior to diagnosis, with 917 (12.3\%) visiting an emergency department 5 or more times before diagnosis. Approximately one-third $(2,542 ; 34.0 \%)$ of patients had undergone gastrointestinal surgery, of whom 1,997 (48.9\%) had CD and 545 (16.1\%) UC $(P<0.001)$. In total, 1,010 patients $(39.8 \%)$ required a stoma following surgery (CD: 580 [29.1\%] vs. UC: 430 [78.9\%]; $P<0.001)$, with half $(514 ; 50.9 \%)$ still having a stoma at the time of the survey (CD: 317 [54.7\%] vs. UC: 197 [45.8\%]; $P<0.001)$.

Fewer than a quarter $(1,748 ; 23.7 \%)$ of respondents described their disease as being in remission in the previous 3 months, with 1,646 (22.3\%) describing more than 5 flares or continuous activity in the preceding year. As a result, 2,038 patients $(27.7 \%)$ had been admitted to hospital over the course of that year. In the preceding 2 years, 1,828 patients with CD (47.1\%) and 1,612 with UC (51.5\%) had received steroids $(P=0.001)$, with $1,969(57.4 \%)$ patients taking steroids for longer than 3 months as a single course (Supplementary Fig. 1). More patients with CD than UC were taking anti-depressants (17.5\% [597] vs. 14.7\% [422], respectively; $P=0.004)$ and analgesics $(31.8 \%[1,084]$ vs. $21.3 \%[604]$; $P<0.001)$.

\section{Effect of Disease on Work and Life}

Inability to work due to IBD obliged 638 patients (8.5\%) either to retire early or go on long-term sick leave. Unemployment rates for those with IBD were higher than contemporaneous national averages in 2 of the 8 countries (Italy: 15.7\%

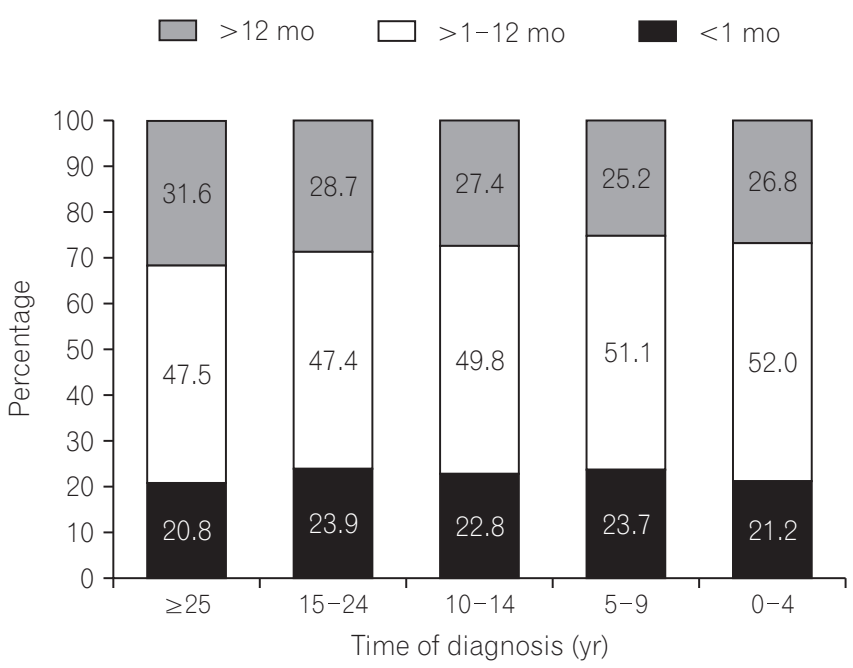

Fig. 1. Period of time between first seeking medical care for symptoms and confirmed diagnosis $(n=7,507)$. $P=0.319$ for difference in time to diagnosis over study period (Kruskal-Wallis $\mathrm{H}$ test). vs. $12.1 \%$, respectively, $P<0.01$; and Germany: $5.7 \%$ vs. $5.0 \%$, $P=0.450$ ) (Supplementary Fig. 2). For those in work or studying $(5,080), 2,906(57.2 \%)$ reported that they had to take time off due to their disease in the preceding 12 months, with a higher rate for those with CD $(1,622 / 2,694 ; 60.2 \%)$ than UC $(1,284 / 2,386 ; 53.8 \% ; P<0.001)$. The median number of days missed for all respondents was 2 (range, $0-25$ ), while for those who reported absenteeism it was 8 (range, 1-25), and IBD-related symptoms prevented 4,935 patients $(69.0 \%)$ from undertaking normal activities for 18 days (range, 1-25) in the preceding year. Over half of patients in the United Kingdom and Germany $(1,738)$ reported that their symptoms resulted in significant fatigue more than half of the time $(1,196 ; 69.4 \%)$, significant pain $(994 ; 58.7 \%)$, nocturnal waking $(938 ; 54.9 \%)$, or anxiety or depression $(910 ; 53.5 \%)$.

\section{Organization of Care}

Around three-quarters $(4,589 ; 74.0 \%)$ of respondents normally consulted a gastroenterologist about their care. Of the remainder, $502(8.1 \%)$ consulted a primary care physician, $442(7.1 \%)$ a specialist nurse, $396(6.4 \%)$ a surgeon, and 274 (4.4\%) a non-gastroenterology hospital physician. Whilst a gastroenterologist was the primary point of care in all countries, there was considerable variation, ranging from $50.4 \%$ (404/802) of patients in the United Kingdom compared to 91.9\% (799/869) in France (Fig. 2). Care was most often received in a general hospital $(3,089 ; 49.8 \%)$, followed by university hospital $(1,603 ; 25.9 \%)$, local surgery/healthcare clinic $(833 ; 13.4 \%)$, and private clinic or hospital $(673 ; 10.9 \%)$.

Contact with their healthcare provider (IBD professional) was more commonly through regular review $(3,073 ; 53.3 \%)$ than ad hoc telephone calls $(2,307 ; 40.0 \%)$ or e-mail (384; $6.7 \%)$. Most reviews were carried out face-to-face $(5,398$; $89.7 \%)$, with only $623(10.3 \%)$ having their last review over the telephone, via email, or postal questionnaire. Nearly a quarter $(1,405 ; 23.4 \%)$ of respondents felt that their last review was not long enough, with 3,529 (58.6\%) having a review lasting 15 minutes or less. Some patients (990; 14.1\%) did not have a regular review organized, with nearly half of these $(441 ; 45.9 \%)$ feeling that this was unacceptable. Nearly three-quarters $(4,858 ; 73.0 \%)$ of respondents who were not already doing so indicated that they would like to communicate to their doctor or nurse through online chat. Overall, over half of patients $(3,737 ; 56.3 \%)$ responded that they felt the healthcare system in their country needs to be much better at using modern information technology.

In the event of a disease flare, patients generally sought advice from their usual provider of care (Spearman correlation 
$0.464 ; P<0.001)$. A quarter of respondents $(1,610 ; 24.6 \%)$ had to wait 4 or more days to receive this advice. Advice provided by email or telephone was significantly quicker than face-toface advice $(P<0.001$ in either case). A second opinion about their IBD had been sought by 1,102 patients (17.4\%) within the preceding year.

When admitted to hospital, almost half the patients $(2,040$; $41.5 \%$ ) were not on a specialist gastroenterology ward. Irrespective of admission to a specialist or non-specialist ward, about a third of respondents $(1,745 ; 35.5 \%)$ felt that there were too few toilets available.

\section{Information Provision and Access to Multidisciplinary Team}

Approximately a quarter of patients (excluding those who could not remember) had not had a discussion about the basic characteristics of IBD $(1,743 ; 24.4 \%)$ or about treatment goals $(1,930 ; 27.4 \%)$ within 3 months of diagnosis (Fig. $3)$. Approaching half $(2,848 ; 40.5 \%)$ had not discussed the benefits or risks of treatment options. The impact of smoking was discussed with only 2,623 (37.4\%) of respondents (CD, $1,909$ [49.4\%]; UC, 714 [22.7\%]; $P<0.001)$. Only a quarter $(1,921 ; 27.3 \%)$ recalled discussion about how IBD might affect education or employment.

Despite a relatively high level of involvement in decisions about their treatment (always/nearly always: 4,987; 72.9\%), the ability to ask important questions $(5,608 ; 81.3 \%)$ or ask for a second opinion (3,088; 45.9\%) (Supplementary Fig. 3), only half the respondents $(3,524 ; 50.9 \%)$ described their healthcare providers as communicating with them in an excellent or very good way. Approaching a quarter $(1,543$;

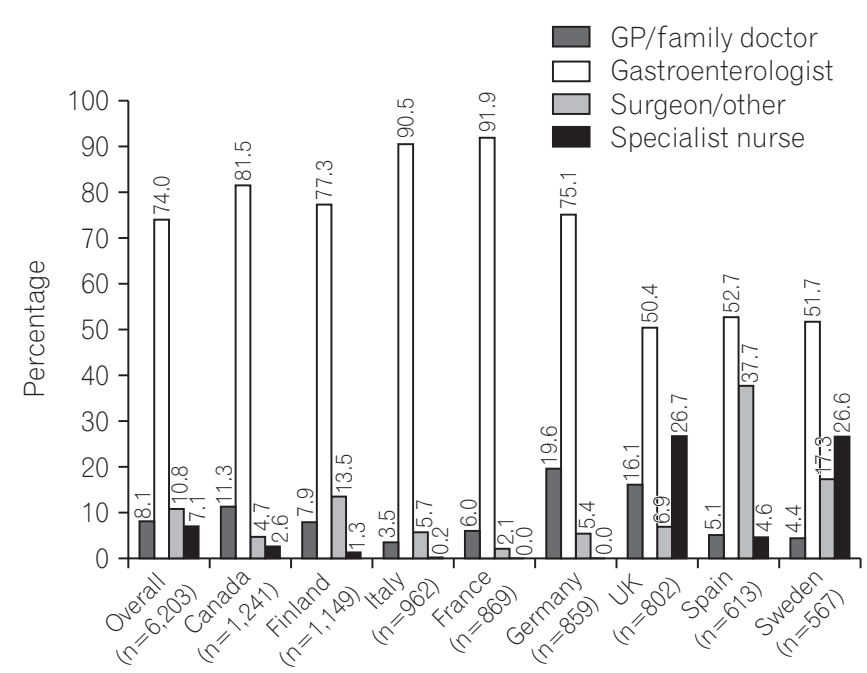

Fig. 2. Primary healthcare provider for respondents.
$22.4 \%$ ) of patients had experienced healthcare professionals who had failed to share important information about their medical history or treatment in the preceding year. Sufficient discussion of relevant issues was sometimes lacking during consultations (e.g., current symptoms insufficiently discussed [749; 11.8\%]; medical treatments [1,027; 16.2\%]; general lifestyle issues [2,819; 44.8\%]) (Supplementary Fig. 4). Nearly half the patients $(3,019 ; 48.1 \%)$ had also not had discussion about the main goals of their treatment.

A third or fewer patients had access to clinical nurse specialists $(2,178 ; 32.8 \%)$, dieticians $(1,358 ; 20.8 \%)$, psychologists $(837 ; 13.0 \%)$, counsellors $(323 ; 6.1 \%)$, or social workers (302; 4.8\%), with significant differences between countries $(P<0.001$ for all except rheumatologist $[P=0.022]$ or social worker $[P=0.720]$ ) (Fig. 4 ). Of those who did not have access to a particular professional, many felt they had an unmet need: dieticians $(2,449 ; 47.5 \%)$, psychologists $(1,851 ; 33.1 \%)$, counsellors $(1,535 ; 30.7 \%)$, clinical nurse specialists $(1,127$; $25.3 \%)$, social workers $(919 ; 15.4 \%)$. A higher proportion of male than female respondents indicated access as not needed for 6 of 8 types of healthcare professional (all $P<0.05$ ), but the former indicated a higher unmet need for access to a colorectal surgeon $(P<0.001)$ (Supplementary Table 3$)$.

\section{Perception of Quality of Care}

Half $(3,429 ; 50.0 \%)$ the respondents rated their care as excellent or very good, with only 358 patients $(5.2 \%)$ considering their care poorly coordinated (Fig. 5). Similar patterns were seen for CD and UC ("excellent" and "very good" vs. "fair" and

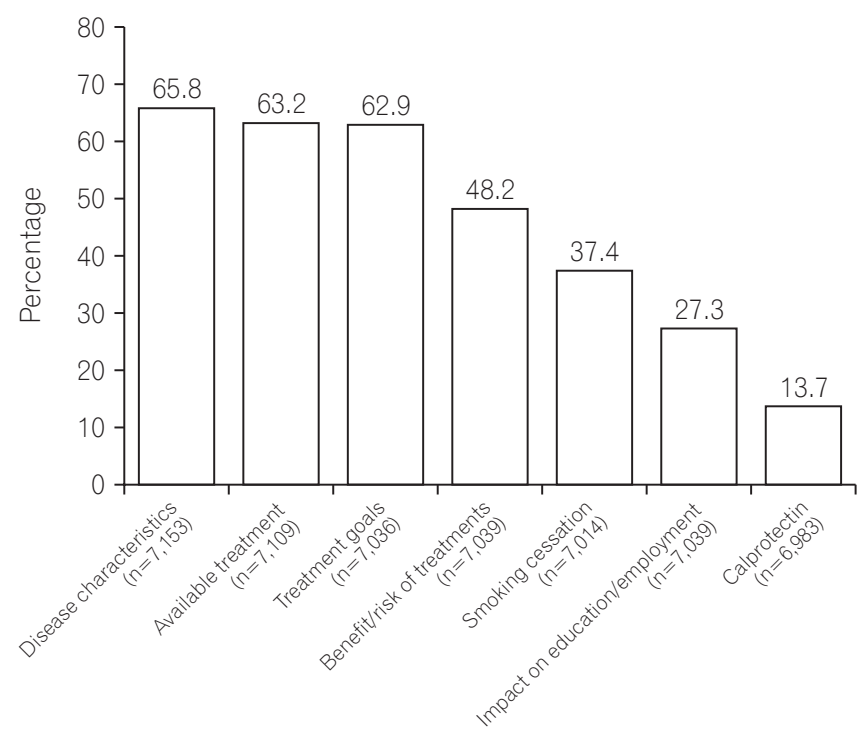

Fig. 3. Important topics in IBD discussed by healthcare provider and respondent within 3 months of diagnosis. 


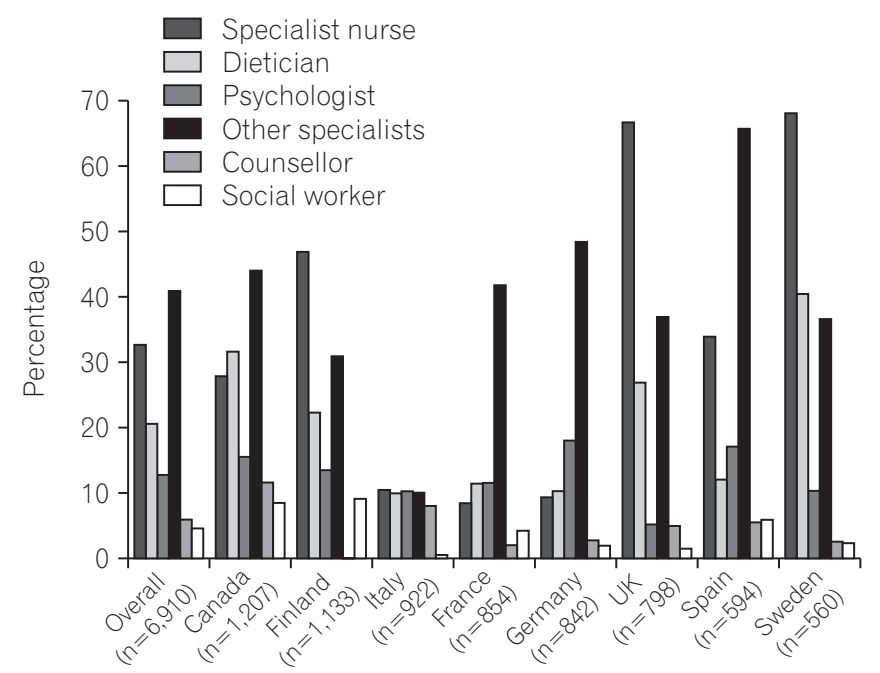

Fig. 4. Respondents' access to healthcare professionals. Other specialists include: rheumatologist and dermatologist. Significant differences (Mann-Whitney $U$-test) between countries for all specialties $(P<0.001)$, except rheumatologist $(P=0.022)$ or social worker $(P=0.720)$.

"poor"; $P=0.003)$, and across countries $(P<0.001)$.

Five factors were significantly associated with perceived excellent or very good quality of care: (1) quality of specialist communication (excellent: OR 128.9, $P<0.001$; very good: OR 41.7, $P<0.001$; good: OR 6.6, $P<0.001$ ); (2) whether the review consultation was long enough (yes: OR 1.8, $P<0.001$ ); (3) failure to share information in the past 2 years (no: OR 1.7, $P<$ 0.001 ; yes: OR 0.7, $P=0.038$ ); (4) no access to a dietician (OR $0.7, P=0.003$ ); and (5) speed of advice in case of flare (same day: OR 1.6, $P=0.006$ ). The 5 factors were rated similarly by both sexes, though quality and speed of communication appeared more important to females, whilst failure to share information and access to a dietician appeared more important to men (Supplementary Table 4). Factors not significantly associated with quality of care included: frequency of regular review; coordination of care; how advice received in the event of a flare; access to MDT; primary/main healthcare professional consulted; usual place of care.

\section{DISCUSSION}

The IBD2020 survey included over 7,500 patients from 8 countries and provides insights into delivery of care, perceived quality of care and areas for improvement. Overall, half the respondents rated their care as excellent or very good, with similar results reported for those with CD or UC and between countries. The most important driver of quality of care identified from the patients' perspective was communication with their healthcare provider $(P<0.001)$. Disap-

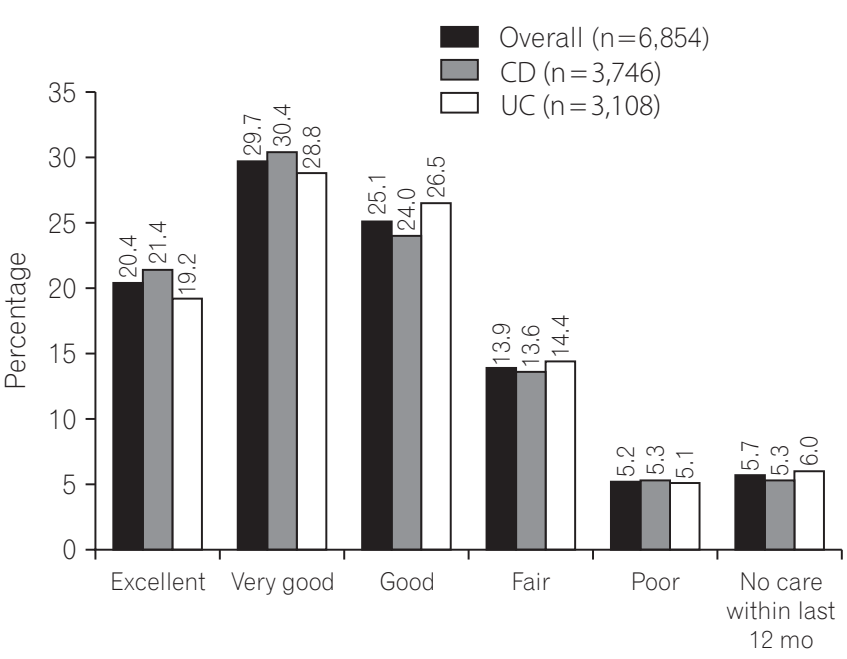

Fig. 5. Respondent rated quality of care. $P=0.003$ for difference in high (excellent and very good) and low (fair and poor) quality of care for CD and UC (Mann-Whitney U-test).

pointingly, only half the patients (50.9\%) described communication as excellent or very good.

Poor communication included insufficient discussion about fundamental aspects of patients' care within 3 months of diagnosis, including characteristics of IBD (24.4\%), treatment goals (27.4\%), or risks-benefits of treatment (40.5\%). Half the patients with CD (50.6\%) could not recall being told about the importance of avoiding smoking, despite well-established risks associated with smoking and exacerbation of CD. ${ }^{25,26}$ For patients with established disease, communication deficits in the preceding 12 months included insufficient discussion of the goals of treatment (48.1\%), general lifestyle issues $(44.8 \%)$, medical treatment options ( $16.2 \%)$, or current symptoms (11.8\%). Inadequate sharing of information between healthcare professionals was reported by nearly a quarter of the patients $(22.4 \% ; P<0.001)$. Dissatisfaction with patient-provider communication has been reported in other patient surveys. ${ }^{6,22,27,28}$ In the IMPACT survey of 4,670 patients with IBD from 25 European countries, $64 \%$ of respondents believed that their gastroenterologist should have asked more probing questions to understand their disease ${ }^{28} \mathrm{~A}$ similar response (68.6\%) to the same question was found when the IMPACT survey was repeated in 172 Japanese patients with IBD ${ }^{27}$ Similarly, in survey by the European Federation of Crohn's and Ulcerative Colitis Associations (EFCCA), $47.8 \%$ of 5,576 patients with IBD reported that their physician did not ask about the impact of symptoms on their quality of life. ${ }^{22}$

Improved healthcare professional-patient communication 
through awareness, education and training should facilitate patients' understanding of the benefits and risks of treatment, potentially leading to increased adherence and better disease outcomes. Most communication was by planned, face-to-face reviews (53.3\% of contacts were reviews of which $89.7 \%$ were face-to-face), but almost a quarter of patients $(23.4 \%)$ felt that their last review was not long enough $(58.6 \% \leq 15$ minutes; $P<0.001)$. Speed of advice in event of a flare was identified as a key driver of good quality of care $(p=0.006)$. Inadequate access to their IBD professional has been identified as an area for improvement in other European surveys, ${ }^{28,29}$ but not in the Japanese IMPACT survey, where $79.1 \%$ felt access was adequate. ${ }^{27}$ It may be unrealistic to expect face-to-face consultations in busy clinics to be extended, but improved access through telephone or email could help. Our survey confirms that advice by telephone or email was significantly faster than face-to-face consultation (both $P<0.001$ ).

Empowering and encouraging patients to be more forthcoming during consultations with healthcare providers (e.g., through the use of coaching programmes $)^{30}$ represents another strategy to improve communication. The IBD2020 survey indicates that respondents felt a high level of involvement in decisions about their treatment (always/nearly always: $72.9 \%$ ), including the ability to ask important questions (81.3\%). In the IMPACT surveys, however, half (Europe, 54\%; Japan, $45.9 \%$ ) the respondents had not felt able to tell their physician something important about their illness ${ }^{27,28}$ while $44.1 \%$ of patients in the EFCCA survey were not prepared to initiate discussions with their physician on the impact of symptoms on their quality of life. ${ }^{22}$ Nevertheless, once a patient had raised such questions with their physician, most $(79.6 \%)$ felt that action would be taken. ${ }^{22}$

Access to multidisciplinary care, a central tenet of IBD quality standards ${ }^{7,13}$ varied considerably across countries, given differences in healthcare systems. Interestingly, the speciality associated with good quality of care other than the lead IBD professional (a gastroenterologist in $74.0 \%$ ) was access to a dietician $(P=0.003)$. Yet overall, $20.8 \%$ of patients had access to a dietician (ranging from $40.6 \%$ in Sweden to $10.0 \%$ in Italy), whilst $47.5 \%$ of those who did not have access felt the need for such contact. A third of respondents also wanted access to psychologists (33.1\%) or counsellors (30.7\%), suggesting that for these patients, emotional needs were not being addressed adequately, which, in turn, affected their perception of quality of care. Two-thirds of respondents $(67.2 \%)$ did not have access to a clinical nurse specialist, though, perhaps surprisingly, only a quarter of these patients (25.3\%) felt that they had the need. This suggests that patients consider the nurses' role to be mostly clinical, supporting that of the gastroenterologist. It may be a case of "not knowing what you're missing," since the support that IBD specialist nurses provide is a well-recognized component of quality care. ${ }^{7,13,31}$ Nurse-led IBD helplines are an example of how patient-provider communication can be facilitated.

Despite increased awareness of IBD allied to a rising disease burden, there appeared to be no improvement in the time to diagnosis over the past 25 years. Many patients (56.7\%) had to seek emergency care prior to diagnosis and at least 5 times in $12.3 \%$. Similar results were reported in the IMPACT survey, where $45 \%$ of respondents received their final diagnosis after more than a year, $67 \%$ attending an emergency department prior to diagnosis and $7 \%$ more than 10 times. ${ }^{27}$ Delays in diagnosis of IBD have been reported in other surveys in Europe and Asia. ${ }^{22,27,32,33}$ More widespread use of fecal calprotectin alongside increased recognition of symptoms and "red flags" within primary and emergency care might facilitate referral of appropriate patients to IBD specialists. $^{34,35}$

There are several limitations to the IBD2020 survey. The open call to contribute via patient organizations will have introduced selection bias, apart from obviating a response rate. There was a preponderance of both female respondents (68.6\%) and patients with CD (54.6\%), as in the IMPACT (66\% and 62\%, respectively) and EFCCA surveys (56.9\% and $56.5 \%),{ }^{22,28}$ suggesting that this is a common bias in questionnaire-based studies in IBD conducted in Europe. In contrast, patient surveys conducted in Asia appear to have the opposite bias in terms of gender (approximately two-thirds male respondents). ${ }^{27,33}$ The survey relied on patient recall, while the coarseness of some time intervals captured in the questionnaire are other inherent limitations. As is to be expected, representation was skewed towards patients with more severe disease who might have more motivation to participate. It should also be noted that none of these surveys have provided benchmarks for Quality of Care against which patients could gauge the care received.

Patient perception of quality of care in the IBD2020 survey was dominated by the quality of communication with the main healthcare provider, most often a gastroenterologist. Nevertheless, this is the single most important factor open to improvement. Rapid access to care, particularly during a potential flare, was also rated highly. Telephone advice lines and electronic media are practical ways of providing patients with reassurance that help and advice is readily available. In 
terms of organization of care, access to a MDT was perceived by patients to be less important than access to specific specialties, in particular a dietician. Information from the IBD2020 survey provides a baseline of patient perception against which strategies aimed at quality improvement in IBD can be gauged.

\section{FINANCIAL SUPPORT}

IBD2020 has received support from AbbVie, Bühlmann, Enterome, Hive, StratX, KPMG, Health Soultions and Veryday.

\section{CONFLICT OF INTEREST}

No potential conflict of interest relevant to this article was reported.

\section{AUTHOR CONTRIBUTION}

S.P.L.T., P.I., J.B., R.D., and M.O. contributed to the concept and design of the study. R.D. organized the IBD2020 survey and J.R.F., J.B. and B.S.R-G. performed the analysis. All authors contributed to the manuscript.

\section{ACKNOWLEDGEMENTS}

We sadly acknowledge the untimely death of Richard Driscoll, one of the co-authors of this study and a Director of IBD2020 (UK Charity 1172495), who, through his work as CEO of Crohn's and Colitis UK (formerly the National Association for Crohn's and Colitis) and other projects, including Director of Development for the UK IBD Registry, made an enormous impact on the lives of patients with IBD.

\section{REFERENCES}

1. Molodecky NA, Soon IS, Rabi DM, et al. Increasing incidence and prevalence of the inflammatory bowel diseases with time, based on systematic review. Gastroenterology 2012;142:46-54. e42.

2. Alrubaiy L, Arnott I, Protheroe A, Roughton M, Driscoll R, Williams JG. Inflammatory bowel disease in the UK: is quality of care improving? Frontline Gastroenterol 2013;4:296-301.

3. David G, Gunnarsson CL, Lofland J, Goodney P, Siegel CA. Mo1362 Geographic variation in care of patients with inflammatory bowel disease suggests unequal quality of care in the United States. Gastroenterology 2013;144(5 Suppl 1):S-647.
4. Weaver KN, Kappelman MD, Sandler RS, et al. Variation in care of inflammatory bowel diseases patients in Crohn's and Colitis Foundation of America Partners: role of gastroenterologist practice setting in disease outcomes and quality process measures. Inflamm Bowel Dis 2016;22:2672-2677.

5. Vienne A, Simon T, Cosnes J, et al. Low prevalence of colonoscopic surveillance of inflammatory bowel disease patients with longstanding extensive colitis: a clinical practice survey nested in the CESAME cohort. Aliment Pharmacol Ther 2011;34:188-195.

6. Wilson B, Lonnfors S, Hommes DW, et al. P406 A European Crohn's and ulcerative colitis patient life IMPACT survey. J Crohns Colitis 2012;6(Suppl 1):S171.

7. Bouguen G, Peyrin-Biroulet L. Surgery for adult Crohn's disease: what is the actual risk? Gut 2011;60:1178-1181.

8. Mikocka-Walus A, Andrews JM, Rampton D, Goodhand J, van der Woude J, Bernstein CN. How can we improve models of care in inflammatory bowel disease? An international survey of IBD health professionals. J Crohns Colitis 2014;8:1668-1674.

9. Benchimol EI, Cook SF, Erichsen R, et al. International variation in medication prescription rates among elderly patients with inflammatory bowel disease. J Crohns Colitis 2013;7:878-889.

10. Song HK, Lee KM, Jung SA, et al. Quality of care in inflammatory bowel disease in Asia: the results of a multinational webbased survey in the 2(nd) Asian Organization of Crohn's and Colitis (AOCC) meeting in Seoul. Intest Res 2016;14:240-247.

11. Adult inflammatory bowel disease physician performance measures set. American Gastroenterological Association Web site. http://cinergi-ibd.com/uploads/1/0/4/9/104927151/ibd_ performance_measures.pdf. Accessed March 9, 2018.

12. Melmed GY, Siegel CA, Spiegel BM, et al. Quality indicators for inflammatory bowel disease: development of process and outcome measures. Inflamm Bowel Dis 2013;19:662-668.

13. Standards for the healthcare of people who have inflammatory bowel disease (IBD) 2013 update. The IBD Standards Group Web site. http://s3-eu-west-1.amazonaws.com/files.crohnsandcolitis.org.uk/Publications/PPR/ibd-standards.pdf. Accessed March 9, 2018.

14. Kim AH, Roberts C, Feagan BG, et al. Developing a standard set of patient-centred outcomes for inflammatory bowel disease: an International, Cross-disciplinary Consensus. J Crohns Colitis 2018;12:408-418.

15. Walsh AJ. TrueColours ulcerative colitis. HRA Web site. https:// www.hra.nhs.uk/. Accessed March 9, 2018.

16. Crandall W, Kappelman MD, Colletti RB, et al. ImproveCareNow: the development of a pediatric inflammatory bowel disease improvement network. Inflamm Bowel Dis 2011;17:450-457. 
17. IBD Qorus: quality driven. Care focused. Crohn's \& Colitis Foundation Web site. http://www.crohnscolitisfoundation.org/ science-and-professionals/ibdqorus/. Accessed March 9, 2018.

18. Regueiro M, Click B, Holder D, Shrank W, McAnallen S, Szigethy E. Constructing an inflammatory bowel disease patient-centered medical home. Clin Gastroenterol Hepatol 2017;15:11481153.e4.

19. Kosinski L, Baum C, Brill J, et al. P-052 Project sonar: patient engagement reduced relative risk and cost of care in an attributed cohort of patients with Crohn's disease. Inflamm Bowel Dis 2017;23:S22.

20. My medical record for inflammatory bowel disease patients. University Hospital Southampton NHS Foundation Trust Web site. https://health.org.uk/programmes/innovating-improvement/projects/my-medical-record-\%E2\%80\%93-inflammatory-bowel-disease. Accessed March 9, 2018.

21. Walters S. NACC audit of IBD. Chichester: Aeneas Press, 2000.

22. Ghosh S, Mitchell R. Impact of inflammatory bowel disease on quality of life: results of the European Federation of Crohn's and Ulcerative Colitis Associations (EFCCA) patient survey. J Crohns Colitis 2007;1:10-20.

23. Eurostat: employment and unemployment. European Commission Web site. http://ec.europa.eu/eurostat/en/web/lfs/ statistics-illustrated. Updated 2014. Accessed March 9, 2018.

24. Canada employment rate. Trading Economics Web site. https:// tradingeconomics.com/canada/unemployment-rate. Updated 2014. Accessed March 9, 2018.

25. Kuenzig ME, Lee SM, Eksteen B, et al. Smoking influences the need for surgery in patients with the inflammatory bowel diseases: a systematic review and meta-analysis incorporating disease duration. BMC Gastroenterol 2016;16:143.

26. Parkes GC, Whelan K, Lindsay JO. Smoking in inflammatory bowel disease: impact on disease course and insights into the aetiology of its effect. J Crohns Colitis 2014;8:717-725.
27. Ueno F, Nakayama Y, Hagiwara E, Kurimoto S, Hibi T. Impact of inflammatory bowel disease on Japanese patients' quality of life: results of a patient questionnaire survey. J Gastroenterol 2017;52:555-567.

28. Lönnfors S, Vermeire S, Greco M, Hommes D, Bell C, Avedano L. IBD and health-related quality of life: discovering the true impact. J Crohns Colitis 2014;8:1281-1286.

29. Schoultz M, Macaden L, Watson AJ. Co-designing inflammatory bowel disease (IBD) services in Scotland: findings from a nationwide survey. BMC Health Serv Res 2016;16:231.

30. Panés J, O’Connor M, Peyrin-Biroulet L, Irving P, Petersson J, Colombel JF. Improving quality of care in inflammatory bowel disease: what changes can be made today? J Crohns Colitis 2014;8:919-926

31. Hernández-Sampelayo P, Seoane M, Oltra L, et al. Contribution of nurses to the quality of care in management of inflammatory bowel disease: a synthesis of the evidence. J Crohns Colitis 2010;4:611-622.

32. Haapamäki J, Turunen U, Roine RP, Färkkilä MA, Arkkila PE. Finnish patients with inflammatory bowel disease have fewer symptoms and are more satisfied with their treatment than patients in the previous European survey. Scand J Gastroenterol 2008;43:821-830.

33. Kim YS, Jung SA, Lee KM, et al. Impact of inflammatory bowel disease on daily life: an online survey by the Korean Association for the Study of Intestinal Diseases. Intest Res 2017;15:338344.

34. Faecal calprotectin diagnostic tests for inflammatory diseases of the bowel: diagnostics guidance [DG11]. National Institute for Health and Care Excellence (NICE) Web site. https://www. nice.org.uk/guidance/dg11. Updated 2013. Accessed March 9, 2018.

35. Walker GJ, Moore L, Heerasing N, et al. PTH-092 Clinical validity and utility of faecal calprotectin in primary care. Gut 2017; 66:A252. 